\title{
Curriculum needs redesigning; enforced by changes of interest in career planning of medical students from year 1 to year 5
}

\author{
H. Ömer Tontuş $a *$, Müberra Karabey ${ }^{b}$, Nağman Gürdal $b$ \\ a Department of Medical Education, Medical Faculty, Ondokuz Mayis University, Samsun, Turkey \\ $b^{b}$ Year 4 Student, Medical Faculty, Ondokuz Mayis University, Samsun, Turkey
}

\section{ARTICLE INFO}

\section{Article History}

Received

$25 / 10 / 2010$

Accepted

$02 / 12 / 2010$

\section{* Correspondence to:}

H. Omer Tontus

Ondokuz Mayis University, Medical

Faculty, Medical Education Department

Samsun, Turkey

e-mail: otontus@omu.edu.tr

\section{Key Words : \\ Career Choice \\ Education \\ Medical \\ Undergraduate}

\section{ABSTRACT}

To assess Year 1, Year 3 and Year 5 medical students' interest in a career in different specialities. Little research addresses how medical students develop their choice of speciality training in Turkey. The purpose of this research was to clarify factors considered by medical students when planning their specialty choice. Interest and expectation questionnaire to 243 students in Ondokuz May1s University Medical Faculty in their 1st, 3rd and 5th year of education. Analysis of the collected data from 243 medical students in the same medical faculty. Data collected by paper based questionnaire from three different school year students in educational year 2009-2010. Although, Year 5 students' aiming towards to Clinical Sciences by $76.47 \%$, Year 1 students choose Surgical Sciences for their postgraduate career by $61.65 \%$. In their mind, Students started their undergraduate medical education as Surgeon but graduated as Clinical Specialist. Most prominent factor on choosing career is personal interest and personal skills for all students groups. Most wanted speciality is Ophthalmology for all cumulative groups. Departmental director of the medical specialties trying to influence on students positively in favour of their department as a career choice. But the students' choice is enhanced by own interest and skills. Our findings may be useful to medical faculty and governments and professional medical organizations as a whole are taking actions to make better futuristic plan for community.

J. Exp. Clin. Med., 2010; 27:94-98

\section{Introduction}

Choosing career is one of the most important discriminator for medical students' later life. The topic of speciality choice has received attention in the literature at least for 50 years. Starting from Year 1 (Y1) students are trying to find best option to suit their expectation. In Turkey, health service on first step is community based medicine and it is dominated by general practitioners or family medicine specialists. But prestigious position of having specialist degree and widening powerful private practice hospital service pushing the medical student from practitioners side to specialist side, progressively. In the questionnaire, we found that general practice was the one of the least preferred career choice among medical students'. As is expected, students make career choices based on their clerkship experiences; however, less is known about the extent to which ambulatory-based or community-based education influences career preference, or about which aspects of these experiences are most valued (Nicholas et al., 2001). Multiple variables affect medical speciality choice, including temperament, sociodemographic factors, and personal experiences (Vaidya et al., 2004). Given these considerations, we composed a set of questions on the students' expectation and experience to probe the following questions: Which factor is having most important influence to choose career? Which specialities are preferred by students? Are there any differences on choosing career by students' educational year?

\section{Design and Methods}

We administered a questionnaire to first year (Y1), third-year (Y3) and fifth year (Y5) students in Ondokuz Mayıs University Medical Faculty (OMU/MF) during the academic year 2009-2010. This was mainly an expectation questionnaire trying to learn students' career plan on their minds that was completed at the first half of educational year 2009-2010. The questionnaire consists of three consecutive questions in regarding feelings about career 
choice. Question 1 and 2 were best choice question. The third question scored by Likert-type scale from 1 to 5 . It then proceeded with the specific career plan question which consists of 42 specialities. All listed specialities are running in OMU/MF. Students give marks to most wanted 3 specialities as first, second and third choice. Given answers rated by 3 point for first choice, 2 point for second choice and 1 point for third choice. Then points are calculated for Y1, Y3, Y5 seperately and for all group totally.

\section{Results}

The age and sex distribution of the respondents is shown in Table 1 below. Mean age of these students was 20.25 (SD $=2.51)$. There were 131 (53.91\%) male and 112 (46.09\%) female. The questionnaires are dropped off at "students' affair department" for voluntarily participation of students. There were 544 students in Y1, Y3, Y5 and 243 of them $(44.67 \%)$ were joined.

Table 1. Demografic data of groups

\begin{tabular}{|c|r|c|c|c|c|}
\hline Age & & & Average age & Range (year) & SD \\
\hline \multirow{3}{*}{ Sex } & Year 1 students & & 18.53 & $17-25$ & 1.19 \\
& Year 3 students & & 21.43 & $20-37$ & 2.82 \\
& Year 5 students & & 23.20 & $21-27$ & 1.23 \\
& All group & & 20.25 & $17-37$ & 2.51 \\
\hline \multirow{3}{*}{} & Year 1 students & 69 & 64 & 133 & $54.73 \%$ \\
& Year 3 students & 26 & 25 & 51 & $20.99 \%$ \\
& Year 5 students & 36 & 23 & 59 & $24.28 \%$ \\
& All group & 131 & 112 & $\mathbf{2 4 3}$ & \\
& & $\mathbf{5 3 . 9 1 \%}$ & $\mathbf{4 6 . 0 9 \%}$ & & \\
& & & & & Total \\
& & & & & \\
\end{tabular}

Our questionnaire based around 4 major themes that emerge from the responses to the specific future career related questions. The first of these themes is the students' choice of the specialities in three domain; basic medical sciences, clinical sciences and surgical sciences. Overall, 226 students responded this question and $8.41 \%$ choose basic medical sciences, $42.48 \%$ choose clinical sciences and $49.12 \%$ choose surgical sciences (Table 2). Although percentage of the choosing surgical sciences gradually fall from Y1 students (61.65\%) to Y5 students (17.65\%), percentage of the choosing clinical sciences gradually rose from Y1 students $(26.32 \%)$ to Y 5 students $(76.47 \%)$.

The differences are statistically significant (studied by Pearson Chi-Square) between Year 1 and Year 5 groups $(p<0.001)$. Significant dissimilarity also found on data between Year 3 and Year 5 students' choice $(p<0.001)$. As tested by SPSS statistical analysing software (SPSS version 15.0.1) differences between groups' choices are significantly different. Table $2 . b$ indicates how values are different than expected values. Year 1 students' choice on Surgical and Clinical sciences indicates statistically significant difference than expected count. Although expected count was around 64, in total 82 students choose surgical sciences. This difference is statistically significant $(p<0.001)$. Although surgical sciences are chosen by more students comparing with expected count, only 35 students of 57.5 expected students indicated willingness of clinical sciences career plan for future $(\mathrm{p}<0.001)$. One of the other significant statistical difference between expected count $(n=25.3)$ and students choice $(n=9)$ was Year 5 students' lack of enthusiasm on choosing surgical sciences as future career plan $(p<0.001)$. All statistical significance data was studied by chi-square test.

Table 2.a: Which group of sciences will be best for your career plan?

\begin{tabular}{|l|c|c|c|c|}
\hline & Year 1 & Year 3 & Year 5 & TOTAL \\
\hline Basic Medical Sciences & $16(12.03 \%)$ & $0(0.00 \%)$ & $3(5.88 \%)$ & $19(8.41 \%)$ \\
\hline Clinical Sciences & $35(26.32 \%)$ & $22(52.38 \%)$ & $39(76.47 \%)$ & $96(42.48 \%)$ \\
\hline Surgical Sciences & $82(61.65 \%)$ & $20(47.62 \%)$ & $9(17.65 \%)$ & $111(49.12 \%)$ \\
\hline No Response & 0 & 9 & 8 & 17 \\
\hline No Response & 133 & 42 & 51 & 226 \\
\hline
\end{tabular}

Table 2.b: Which group of sciences will be best for your career plan?

\begin{tabular}{|c|c|c|c|c|c|c|}
\hline & \multicolumn{2}{|c|}{ Year 1 } & \multicolumn{2}{c|}{ Year 3 } & \multicolumn{2}{c|}{ Year 5 } \\
\hline & Count & $\begin{array}{c}\text { Expected } \\
\text { Count }\end{array}$ & Count & $\begin{array}{c}\text { Expected } \\
\text { Count }\end{array}$ & Count & $\begin{array}{c}\text { Expected } \\
\text { Count }\end{array}$ \\
\hline Surgical Sciences & 82 & 64.4 & 20 & 21.3 & 9 & 25.3 \\
\hline Clinical Sciences & 35 & 57.5 & 22 & 17.5 & 39 & 21.8 \\
\hline Basic Medical Sciences & 16 & 11.1 & 0 & 3.2 & 3 & 3.9 \\
\hline
\end{tabular}

The purpose of the second question was to determine how medical students' early speciality preferences corresponded to later choice of speciality using a person-oriented versus technique-oriented approach. Person-oriented specialties are considered to be family practice, internal medicine, obstetrics and gynaecology, paediatrics, physical medicine and rehabilitation, and psychiatry, whereas technique-oriented specialties are anaesthesiology, dermatology, emergency medicine, otolaryngology, pathology, radiology, and surgery. Results are shown on Table 3 . There were 223 answers to this question and in all group technique-oriented specialities preferred by students. 138 students $61.88 \%$ of all group indicated technique oriented group is preferred.

The differences are statistically un-important for speciality preferences depending on person-oriented versus technique-oriented ( $p>0.05$ studied by Pearson ChiSquare).

Table 3: When you are choosing a speciality which option suit for you?

\begin{tabular}{|c|c|c|c|c|}
\hline & Year 1 & Year 3 & Year 5 & TOTAL \\
\hline Person-Oriented Specialities & $\begin{array}{c}45 \\
(36.29 \%)\end{array}$ & $\begin{array}{c}19 \\
(40.43 \%)\end{array}$ & $\begin{array}{c}21 \\
(40.38 \%)\end{array}$ & $\begin{array}{c}85 \\
(38.12 \%)\end{array}$ \\
\hline Technique-oriented Specialities & $\begin{array}{c}79 \\
(63.71 \%)\end{array}$ & $\begin{array}{c}28 \\
(59.57 \%)\end{array}$ & $\begin{array}{c}31 \\
(59.67 \%)\end{array}$ & $\begin{array}{c}138 \\
(61.88 \%)\end{array}$ \\
\hline No Response & 9 & 4 & 7 & 20 \\
\hline No Response & 124 & 47 & 52 & $\mathbf{2 2 3}$ \\
\hline
\end{tabular}

Third question was to learn the most important factor for participants in the deciding their career choice. Respondents scored each item from 1 to $5(1=$ strongly agree, $2=$ Agree, $3=$ Unsure, $4=$ Disagree $5=$ strongly disagree). All year students indicated that "personal skills and interest" is the most important factor for career planing. Y1 and Y 5 students marked "short postgraduate education time" has least effect when Y3 marked "academic career advancement ". In total group "short postgraduate education time" was least important factor. The results are presented 
in Table 4. "Personal skills and interest" is the most important factor for medical students in their speciality choice. Dozens of variables affect medical student choice among medical specialties such as social factors, personal experiences, characteristics of each speciality, and medical student personality traits. We tried to learn effect of given 8 factors on choice of specialty.

The differences are found statistically important by Pearson Chi-Square test, for item called "Academic career advancement is important" between Y3 group and other groups $(\mathrm{p}<0.05)$. In another words, Year 3 students doesn't care about their academic advancement when comparing with other groups. Except this, Y3 students are planning to choose a career which with low work load when others indicate this is a one of the least important factor for choosing career.

When comparing Year 1 and Year 3 students' mean scores item by item, three of the items are found statistically different, these are "Personal skills \& interest are important", "Low work load is important" and "Short postgraduate education time is important" $(\mathrm{p}<0.047$, $\mathrm{p}<0.001, \mathrm{p}<0.03$ respectively, all statistical values refer to Pearson Chi-Square test). Between Year 3 and Year 5 students, the only statistically important difference is found on item "Low work load is important" $(\mathrm{p}<0.01)$. When mean scores are compared for Year 1 and Y5 the only significant difference found on item asked as "Low work load is important" $(\mathrm{p}<0.04)$.

Table 4: Which factor has effect on your career choice?

\begin{tabular}{|c|c|c|c|c|}
\hline & Year 1 & Year 3 & Year 5 & TOTAL \\
\hline Personal skills \& interest are important & 1.63 & 1.59 & 1.70 & 1.64 \\
\hline Prestige of speciality is important & 2.93 & 2.19 & 2.70 & 2.78 \\
\hline Academic career advancement is importan & nt 2.60 & 4.22 & 2.852 .80 & \\
\hline $\begin{array}{l}\text { Opportunity to flexible working hours is } \\
\text { important }\end{array}$ & 3.12 & 2.90 & 3.33 & 3.15 \\
\hline Highly paid speciality is important & 3.16 & 3.13 & 3.56 & 3.25 \\
\hline $\begin{array}{l}\text { More patient contact \& communication } \\
\text { chance }\end{array}$ & 3.16 & 3.40 & 3.56 & 3.27 \\
\hline $\begin{array}{l}\text { Low work load is important } \\
\text { Short postgraduate education time is }\end{array}$ & 3.70 & 2.63 & 3.57 & 3.49 \\
\hline important & 3.82 & 3.89 & 4.14 & 3.89 \\
\hline
\end{tabular}

The fourth question was asking to learn the top preferred career choices of students. Students marked three specialities as first, second and third choice. After collecting questionnaire sheets we scored students' choices by giving 3 point for first choice, 2 points for second choice and 1 point for their third choice.

Table 5. Respondents' career choice list by point

\begin{tabular}{|c|l|c|c|c|c|}
\hline & Specialities & Year 1 & Year 3 & Year 5 & TOTAL \\
\hline $\mathbf{1}$ & Ophtalmology & 94 & 28 & 41 & 163 \\
\hline $\mathbf{2}$ & Cardiology & 76 & 23 & 42 & 141 \\
\hline $\mathbf{3}$ & Cardiovascular Surgery & 93 & 14 & 12 & 119 \\
\hline $\mathbf{4}$ & Gynaecology \& Obstetrics & 56 & 26 & 18 & 100 \\
\hline $\mathbf{5}$ & General Surgery & 49 & 13 & 7 & 69 \\
\hline $\mathbf{6}$ & Pediatrics & 39 & 17 & 9 & 65 \\
\hline $\mathbf{7}$ & Plastic \& Reconstructive Surgery & 28 & 12 & 20 & 60 \\
\hline $\mathbf{8}$ & Neurosurgery & 33 & 15 & 0 & 48 \\
\hline $\mathbf{9}$ & Dermatology & 17 & 17 & 12 & 46 \\
\hline $\mathbf{1 0}$ & Radiology & 4 & 15 & 27 & 46 \\
\hline
\end{tabular}

Nearly all students $(n=242,99.58 \%)$ except one Y1 student have intention to go further with a specialist degree after graduating from medical faculty (Table 5). The top preferred career choice of the respondents was Ophthalmology in total group followed by Cardiology, Cardiovascular Surgery and Gynaecology \& Obstetrics (respectively 163, 141, 119 and 100 points). Points of four major medical specialities (General Surgery, Internal Medicine, Gynaecology \& Obstetrics and Paediatrics) are steadily decreased through Y1 to Y5. These results are very identical to results of Dikici et al. Their research indicates that, the three most preferred specialities are cardiology, paediatrics and ophthalmology (Dikici et al., 2008). Similar results in a recent study from Jordan surgery was the choice of $65 \%$ of second year medical students, but only $38 \%$ chose surgery by the final year (Khader et al., 2008). Six departments were without any score (Biophysics, Biostatistics, Histology \& Embryology, Clinical Bacteriology \& Infectious Diseases, Radiation Oncology, and Medical Biology). Which means as students experienced clinically they slowly move to highly specified departments. The data indicates that there were only one respondent choose general practice as his/her first preference and no one choice other than this Y1 student. There was an increase in the points of Radiology from Y1 to $\mathrm{Y} 3$ and $\mathrm{Y} 3$ to $\mathrm{Y} 5$ (4, 15 and 27 points respectively). The students were very interested in the opportunity to specialise. Due to inequality of respondents' number in each groups, we tried to find intensity of choice by dividing specialty points to each year's student's number in survey. Table 6 reflects more accurate result which cleared from groups' number inequality, for top ten chosen specialties. On this table, we found the heaviness of the gradual upward changes on Radiology specialty choice.

Table 6. Respondents' career choice list by density

\begin{tabular}{|l|c|c|c|c|}
\hline $\begin{array}{c}\text { SPECIALITIES } \\
\text { (Points divided by groups'n) }\end{array}$ & $\begin{array}{l}\text { Year 1 } \\
\mathrm{n}=133\end{array}$ & $\begin{array}{l}\text { Year 3 } \\
\mathrm{n}=51\end{array}$ & $\begin{array}{c}\text { Year 5 } \\
\mathrm{n}=59\end{array}$ & $\begin{array}{c}\text { TOTAL } \\
\mathrm{n}=243\end{array}$ \\
\hline $\mathbf{1}$ Ophtalmology & 94 & 28 & 41 & 163 \\
\hline $\mathbf{2}$ Cardiology & 76 & 23 & 42 & 141 \\
\hline $\mathbf{3}$ Cardiovascular Surgery & 93 & 14 & 12 & 119 \\
\hline $\mathbf{4}$ Gynaecology \& Obstetrics & 56 & 26 & 18 & 100 \\
\hline $\mathbf{5}$ General Surgery & 49 & 13 & 7 & 69 \\
\hline $\mathbf{6}$ Pediatrics & 39 & 17 & 9 & 65 \\
\hline $\mathbf{7}$ Plastic \& Reconstructive Surgery & 28 & 12 & 20 & 60 \\
\hline $\mathbf{8}$ Neurosurgery & 33 & 15 & 0 & 48 \\
\hline $\mathbf{9}$ Dermatology & 17 & 17 & 12 & 46 \\
\hline $\mathbf{1 0}$ Radiology & 4 & 15 & 27 & 46 \\
\hline
\end{tabular}

\section{Discussion}

The aim of this study was to examine the speciality choices of medical graduates of the OMU/MF. In Turkey, the specialty status of doctors is an extremely important component of any individual doctor's identity. Choices of potential careers do seem to change during a student's educational year at medical school. The factors behind the choice of speciality, which could be purely professional, but could also include factors such as expected income, prestige, interest in primary care based/ hospital based practice, or other reasons. A varied list of factors of speciality choice studied, including demographic and socioeconomic factors (highly paid, prestigious), academic 
achievement and lifestyle plans (flexibility, low work load). Dozens of variables affect medical student choice among medical specialties. According to Vaidya et al, the categories of variables include sociodemographic factors, personal experiences, characteristics of speciality, and medical student personality traits (Vaidya et al., 2004). Regarding Sherrill, unique environment of the medical school has a major impact on students' perceptions of the practice of medicine and their career decisions (Sherrill, 2004). Medical school often represents the students' first contact with medical culture, the shared understanding and perspective of the medical profession. The future perspective of health care is changing in a rapid manner (Sherrill, 2004). Important decision such as choice of medical career is life changing, complex, stressful and is influenced by a variety of determinants. It is important to consider the career plan which motivate the current generation of medical students in order to successfully promote their practice. In this survey we found almost all of respondents agreed that they would like to be a specialist, based on their "skills and interest" and a career that offers prestigious position.

Score points about radiology as a career choice rose during the educational progression from 4 to 27 points. This is the one of the most prominent step by step change of all groups.

In their literature analysis Bland et al., (1995) indicates following list is important for career choice; students' values and limitations, patient contact, workload, work hours, flexibility, types and diversity of healthcare problems, income, prestige, use of technology, surgery and apparent career satisfaction of current members of specialty (Bland et al., 1995). Early aspirations are eventually mediated by more realistic selections as a person has experiences and learns about his own capacities as well as the realities of the labor market and the resources available. The final choices represent a compromise between the person's interests, capacities and values as well as the opportunities and limitations in the world. In our study, students in early years choose major medical specialities (e.g. General Surgery, Internal Medicine, Gynaecology \& Obstetrics, and Paediatrics) with their early medical sciences aspirations. In further years like Y3 and Y5 in our study, students' choice shifted to newly developed specialities or minor surgical departments as they get aware of their interest and skills.

When designing the questionnaire, theoretically we believe that experiences during medical school are one of the most important influence on career choice. Other factors are personality characteristics and lifetime earnings. Little research has focused specifically on the impact of economic factors on speciality choice, but recent work by health economists has suggested that the potential for higher lifetime earnings increases the probability that a speciality is chosen (Woodward, 1990). Although these studies mention economics factor is a major discriminator for future career plan, in our study group which compromise
243 respondent students this was not the case. For them economic factor was the 5 th in the line of eight.

Depending on Markert et al., (2008) although many factors (eg, academic achievement, financial considerations, and lifestyle preferences) effect on specialty choice, many intrapersonal aspects (interests, values, and personality characteristics) also have an impact on the medical graduate's decision (Markert, 2008). Students respond to the market in making career and education decisions, and career decisions are particularly impacted by the economic fortunes of high-level occupations such as medicine. In contrast to Freeman, we found that our students from early years to year five did not choice "highly paid specialities" as major discriminator for their future plan."Skills and Interest" is chosen as an indicator of their career plans in our study group by Y1, Y3 and Y5 students. Actually, we were surprised to learn that the best predictor of the career plan was not "highly paid specialities" option.

In a Norwegian study by Aasland et al., (2008) "time for family" was received the most important determinant as a factor for specialty choice (Aasland and Røvik, 2008). Many researchers have tried to determine factors that influence students' speciality preferences (Saigal et al., 2007; Yousef, 2008). Some have postulated that the primary influences were students' personal characteristics.

Surgery, internal medicine, paediatrics, and obstetrics and gynaecology were the most speciality preferred preferences among medical students at Jordan University of Science and Technology (Yousef, 2008). But we found that students in early years of education tend to choose this kind of major specialities. In overall, minor surgical specialities are becoming more attractive for students' later educational years.

Another result meriting respect of consideration is the fact that community medicine as a speciality one of the least popular of the speciality choices of all groups. If this predicted results happen when their later life, we will need to find proper answer for problems of community based medicine. Some researcher indicates that medical graduates to select specialties to which they have had more patient contact (T P Lam, 1994).

\section{Conclusion}

The career preferences made by medical students and factors influencing these preferences are of importance to medical workforce planners especially in times of supply more than is needed or less than is needed of doctors ( Yousef, 2008).

Medical students reflect on their personality, values, and interests on their path to making career choices. Students in medical schools do so for a variety of reasons and plan diverse careers. Our results can provide guidance for program development. Students' motivations for electing specialty training and their career choices provide indicators concerning the future of medical practice.

Most importantly, our findings may be useful to 
medical faculty and governments and professional medical organizations as a whole are taking actions to make better futuristic plan for community. We learn from our research that the students making their choice according to their own "skills and interest" emphasise administrative counselling functions should be included in curriculums.

\section{REFERENCES}

Aasland, O.G., Røvik, J.O., Wiers-Jenssen, J., 2008. Motives for choice of specialty during and after medical school. Tidsskr Nor Legeforen. 128, 1833-1837

Bland, C.J., Meurer, L.N., Maldonado, G., 1995. Determinants of primary care specialty choice: A non-statistical metaanalysis of the literature; Acad. Med. 70, 620-641.

Dikici, M.F., Yaris, F., Topsever, P., Filiz, T.M., Gurel, F.S., Cubukcu, M., 2008. Factors effecting chaice of speciality among first-year medical students of four universities in different regions of Turkey; Croat Med. J. 49, 415-420.

Khader Y., Al-Zoubi, D., Amarin, Z., Alkafagei, A., Khasawneh, M., Burgan, S., 2008. Factors affecting medical students in formulating their speciality preferences in Jordan, BMC Medical Education, 8,32 doi:10.1186/1472-6920-8-32, This article is available from: biomedcentral.com/1472-6920/8/32.

Millan, L.R. 2005. What is behind a student's choice for becoming a doctor? CLINICS 60,143-150

Nicholas, J., Paul B.K., Fred, A.M., Ruth P.G., Mitch A.H., 2001. Russell Boyle : Arch. Pediatr. Adolesc. Med. 155, 592-596.

Ronald, J.M., Paul R., Mariam, M.E., Kornelija J., Alexander T.H., Bradley, A.M., 2008. Personality as a Prognostic Factor for Specialty Choice: A Prospective Study of 4 Medical School Classes, Medscape J. Med. 10,49.

Sherrill, W.W., 2004. An analysis of medical student career choice. Medical Education Online, Med. Educ. Online [serial online] 9,14.

Saigal, P., Takemura, Y., Nishiue, T., Fetters, 2007. Factors considered by medical students when formulating their speciality preferences in Japan: findings from a qualitative study. BMC Med. Educ. 11, 7-31.

T P Lam: Speciality Choice Of Medical Graduates, HK Pract 1996; 18, 504-512.

Vaidya, Nutan Atre, Sierles, Frederick S., Raida, Michael D., Fakhoury, Faris J., Przybeck, Thomas R. and Cloninger, C. Robert, 2004. 'Relationship Between Speciality Choice and Medical Student Temperament and Character Assessed With Cloninger Inventory', Teaching and Learning in Med. 16, 150-156

Woodward, C.A., 1990. Developing a Research agenda on career choice in medicine Teach Learn Med. 2, 139-40. 